\title{
Occurrence of potentially zoonotic and cephalosporin resistant enteric bacteria among shelter dogs in the Central and South- Central Appalachia
}

\author{
Ashutosh Verma ${ }^{1,2^{*}}$, Kimberly Carney ${ }^{1,3}$, Marina Taylor ${ }^{1}$, Kaitlyn Amsler ${ }^{1}$, Joey Morgan ${ }^{1}$, Karen Gruszynski ${ }^{1,3}$, \\ Erdal Erol ${ }^{4}$, Craig Carter ${ }^{4}$, Stephan Locke ${ }^{4}$, Ashton Callipare ${ }^{4}$ and Devendra H. Shah ${ }^{*^{*}}$
}

\begin{abstract}
Background: Antimicrobial resistance and presence of zoonotic enteropathogens in shelter dogs pose a public health risk to shelter workers and potential adopters alike. In this study we investigated the prevalence of zoonotic bacterial pathogens and cephalosporin resistant $\left(\mathrm{Cef}^{\mathrm{R}}\right)$ enteric bacteria in the feces of apparently healthy shelter dogs in the Cumberland Gap Region (CGR) in the US states of Kentucky, Tennessee and Virginia.

Results: Fecal samples of 59 dogs from 10 shelters in the CGR of Central and South-Central Appalachia were screened for the presence of Campylobacter jejuni, Clostridium perfringens, Salmonella and Cef ${ }^{R}$ enteric bacteria. C. jejuni, C. perfringens were detected by PCR based assays. Culture and PCR were used for Salmonella detection. Of 59 dogs, fecal samples from 14 (23.7\%) and 8 (13.6\%) dogs tested positive for cpa and hipO genes of $C$. perfringens and $C$. jejuni, respectively. Salmonella was not detected in any of the tested samples by PCR or culture. Cef ${ }^{R}$ enteric bacteria were isolated on MacConkey agar supplemented with ceftiofur followed by identification using MALDI-TOF. Fecal samples from 16 dogs (27.1\%) yielded a total of $18 \mathrm{Cef}^{\mathrm{R}}$ enteric bacteria. Majority of Cef ${ }^{\mathrm{R}}$ isolates $(14 / 18,77.8 \%)$ were $E$. coli followed by, one isolate each of Enterococcus hirae, Acinetobacter baumannii, Acinetobacter pittii, and Pseudomonas aeruginosa. Cef ${ }^{\mathrm{R}}$ enteric bacteria were tested for resistance against 19- or 24-antibiotic panels using broth microdilution method. Seventeen (94.4\%) Cef ${ }^{R}$ bacteria were resistant to more than one antimicrobial agent, and 14 (77.8\%) displayed multidrug resistance (MDR).
\end{abstract}

Conclusions: This study shows that shelter dogs within the CGR not only carry zoonotic bacterial pathogens, but also shed multidrug resistant enteric bacteria in their feces that may pose public health risks.

Keywords: Shelter dogs, Central and South-Central Appalachia, Multi-drug resistance (MDR), Antimicrobial resistance (AMR)

\footnotetext{
*Correspondence: ashutosh.verma@Imunet.edu; dshah@wsu.edu

${ }^{2}$ Center for Infectious, Zoonotic and Vector-borne diseases, Harrogate, USA

${ }^{5}$ Department of Veterinary Microbiology \& Pathology, Washington State University College of Veterinary Medicine, Pullman, Washington, USA Full list of author information is available at the end of the article
} permits use, sharing, adaptation, distribution and reproduction in any medium or format, as long as you give appropriate credit to the original author(s) and the source, provide a link to the Creative Commons licence, and indicate if changes were made. The images or other third party material in this article are included in the article's Creative Commons licence, unless indicated otherwise in a credit line to the material. If material is not included in the article's Creative Commons licence and your intended use is not permitted by statutory regulation or exceeds the permitted use, you will need to obtain permission directly from the copyright holder. To view a copy of this licence, visit http://creativecommons.org/licenses/by/4.0/. The Creative Commons Public Domain Dedication waiver (http://creativeco mmons.org/publicdomain/zero/1.0/) applies to the data made available in this article, unless otherwise stated in a credit line to the data. 


\section{Background}

Cephalosporin-resistant enteropathogens are prevalent worldwide and are a formidable threat to both public and animal health as many exhibit multi-drug resistance (MDR) [1]. This is concerning because extendedspectrum cephalosporins are listed as key antibiotics for treatment of bacterial infections in both humans and animals [2, 3]. Companion animals can serve as a reservoir of anti-microbial resistant (AMR) bacteria that have an increased potential for zoonotic transmission due to their intimate contact with humans [4-7]. While previous research on companion animal reservoirs for AMR has focused on clinically ill animals [4, $8,9]$, the literature on the fecal analysis of healthy dogs, especially shelter dog population in the United States is lacking [10]. The 2019-2020 APPA National Pet Owners Survey reported 19\% dogs obtained from animal shelter/humane society $[9,11]$. Thus, monitoring for the zoonotic pathogens and the AMR in shelter dogs is important for understanding the risk to the human population and the environment.

Population of dogs housed in animal shelters are at increased risk of carrying and spreading a variety of enteric pathogens to both animals and humans. Some of the common enteropathogens of dogs are also important public health pathogens. For instance, Camylobacter jejuni (C. jejuni) is a zoonotic pathogen frequently detected in symptomatic and asymptomatic dogs [12]. A few studies have reported that living with diarrheic pets is a risk factor for campylobacteriosis in humans [13-20].
A recent multi-laboratory survey in the United States showed that $1.3 \%$ symptomatic and $1.1 \%$ asymptomatic dogs shed Salmonella in their feces [21]. Similarly, toxin producing Clostridium perfringens (cpa-positive C. perfringens) is present in diarrheic and healthy dogs and is also considered as potential zoonotic pathogen [22].

Some factors that contribute to the introduction, persistence, and spread of enteric pathogens in animal shelters include high animal population densities, lack of proper veterinary care, stressful and unsanitary housing conditions, limited funding, adoption across state boundaries, and high animal turnover [23]. Cultural and socioeconomic factors unique to the Appalachian Region further complicate these issues and put these animals at a risk of getting infected, becoming carriers, and transmitting diseases to both animals and humans. The objective of this study was to detect occurrence of zoonotic enteropathogens including C. jejuni, Salmonella, cpa-positive C. perfringens and cephalosporin resistant $\left(\mathrm{Cef}^{\mathrm{R}}\right)$ enteric bacteria in the feces of dogs (owner surrender, free-roaming, feral) housed in ten animal shelters across three US states within the Central and South-Central Appalachian Region.

\section{Results}

\section{Population demographics}

Animal attributes of shelter location, sex (male or female), estimated age, and fecal score were recorded at the time of sampling (Table 1). The dogs sampled in this study included 23 (39\%) female, 36 (61\%) male, and had a

Table 1 Demographics of shelter dogs carrying $\operatorname{Cef}^{R}$ enteric bacteria

\begin{tabular}{|c|c|c|c|c|c|c|c|}
\hline Sample ID & $\begin{array}{l}\text { Shelter } \\
\text { ID }\end{array}$ & Breed & $\begin{array}{l}\text { Age } \\
\text { (years) }\end{array}$ & Sex & Fecal Score & Bacterial isolates & $\begin{array}{l}\text { MALDI } \\
\text { scores }\end{array}$ \\
\hline CR01 & $K R$ & Pit mix & 2 & $f$ & 6 & E. coli & 2.51 \\
\hline $\mathrm{CRO2}$ & $\mathrm{KR}$ & Lab mix & 2 & $\mathrm{~m}$ & 4 & E. coli & 2.40 \\
\hline CRO3 & LC & Pitbull & 1 & $\mathrm{~m}$ & 2 & E. coli & 2.54 \\
\hline CRO4 & $\mathrm{LC}$ & Rottweiler mix & 4 & $\mathrm{~m}$ & 3 & E. coli & 2.49 \\
\hline CR05 & LC & Australian shepherd mix & 3 & $\mathrm{~m}$ & 2 & E. coli & 2.33 \\
\hline CR06 & UC & Collie mix & 0.17 & $\mathrm{~m}$ & 3 & E. coli & 2.56 \\
\hline CRO7 & UC & Collie mix & 0.3 & $f$ & 3 & E. coli & 2.49 \\
\hline CR08 & $S L$ & Chihuahua & 5 & $\mathrm{~m}$ & 3 & E. coli & 2.49 \\
\hline CRO9 & $S L$ & Lab & 1.5 & $\mathrm{~m} / \mathrm{n}$ & 3 & E. coli & 2.58 \\
\hline CR11 & $S L$ & Pitbull & 3 & $\mathrm{~m}$ & 5 & E. coli & 2.41 \\
\hline CR12 & $S L$ & Pit/Shepherd mix & 1 & $\mathrm{~m}$ & 3 & E. coliEnterococcus hirae & $\begin{array}{l}2.52 \\
2.32\end{array}$ \\
\hline CR13 & $S L$ & Hound & 1 & $\mathrm{~m}$ & 3 & E. coli & 2.33 \\
\hline CR14 & $\mathrm{JO}$ & Beagle mix & 3 & f & 2 & Acinetobacter baumannii & 2.32 \\
\hline CR15 & JO & Collie & 2 & f & 2 & $\begin{array}{l}\text { Acinetobacter pittii } \\
\text { Pseudomonas aeruginosa }\end{array}$ & $\begin{array}{l}2.35 \\
2.46\end{array}$ \\
\hline CR16 & $\mathrm{KW}$ & Border Collie & 0.42 & $\mathrm{~m}$ & 6 & E. coli & 2.44 \\
\hline CR17 & $\mathrm{KW}$ & Chihuahua mix & 2 & $f$ & 2 & E. coli & 2.51 \\
\hline
\end{tabular}




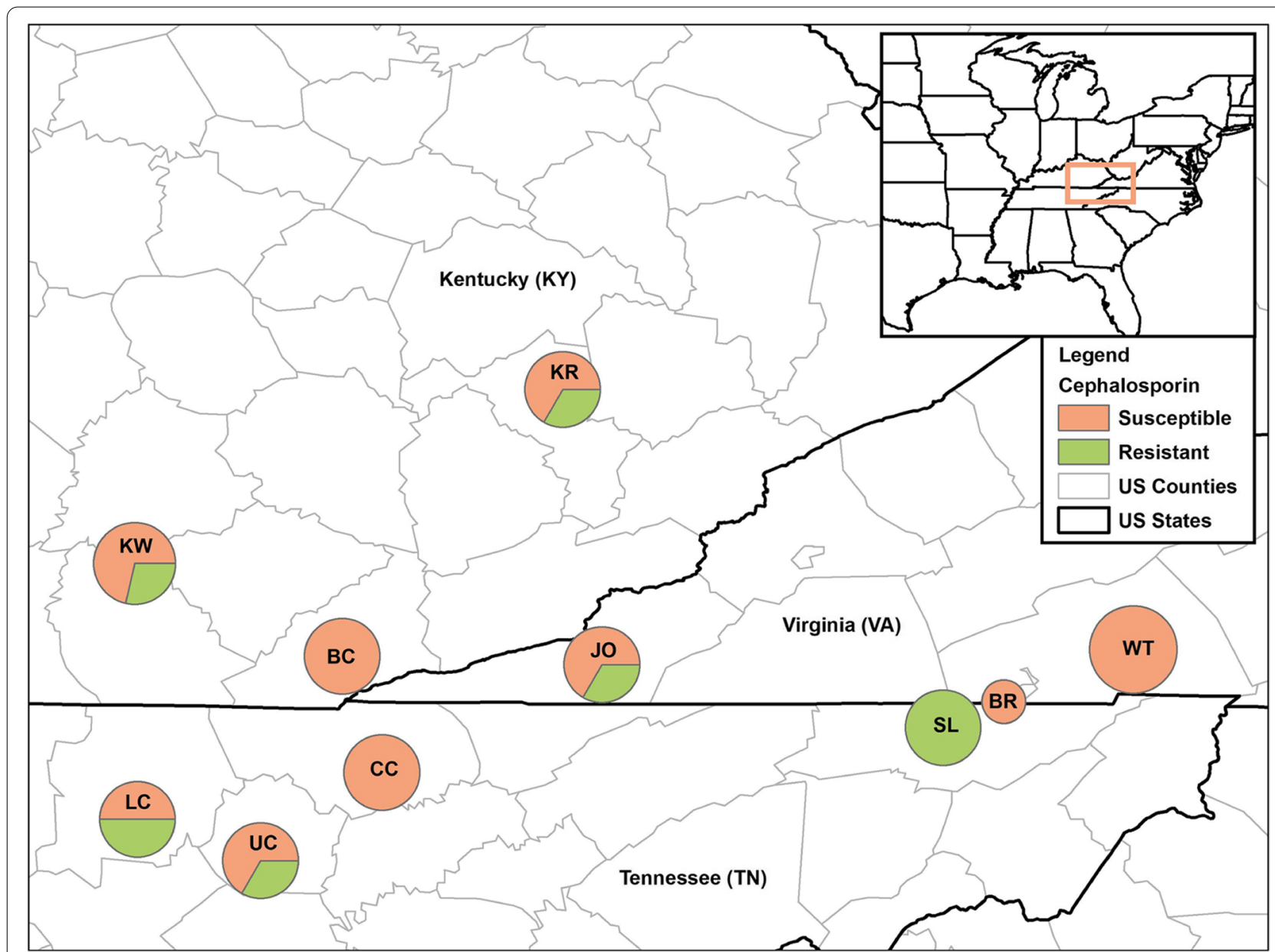

Fig. $1 \mathrm{Cef}^{\mathrm{R}}$ enteric bacteria among shelter dogs. Map depicts the dog shelters in the US states of Kentucky, Tennessee, and Virginia. Fecal samples were collected from 8 dogs from Shelter WT, 7 dogs from Shelter KW, 6 dogs each from Shelters KR, BC, CC, LC, UC, SL, JO, and 2 dogs from Shelter BR. The proportions of Cef ${ }^{R}$ enteric bacteria within each shelter pie chart is shown. Map created with ArcMap 10.6 (Esri, Redlands, CA)

mean age of 2.2 years (range 2 months to 10 years), and a mean fecal score of 2.95 (range 1-6; Purina Fecal Scoring Scale). A fecal score of 1 indicates a hard and dry stool, 3 is normal, and a fecal score of 6 is indicative of a watery stool with no solid composition.

\section{Occurrence of $C$. jejuni, C. perfringens and Salmonella in shelter dogs}

Of the 59 dogs tested in this study, 8 (13.6\%; $95 \%$ CI: 6-30\%) and 14 (23.7\%; 95\% CI: 13.6-36.6\%) were positive for the hipO and cpa genes of C. jejuni and C. perfringens, respectively (Fig. 1). Three dogs were positive for both $C$. jejuni and C. perfringens. None of the dogs were positive for Salmonella by culture or by PCR methods. Out of 10 shelters, $C$. jejuni was detected in fecal samples collected from $3(30 \%)$ shelters while cpa-positive C. perfringens was detected in fecal samples collected from 7 (70\%) shelters. C. jejuni was detected most frequently in the fecal samples $(4 / 8,50 \%)$ collected from KR shelter. Many of the expected counts for chi-square tests were less than 5 due to the low number of samples and positive results except for C. perfringens and sex which was not statistically significant. Therefore, no statistical interpretation can be made regarding the other variables and test results for the sampled shelter dogs.

\section{Occurrence of Ceftiofur-resistant enteric bacteria}

MALDI scores of $\mathrm{Cef}^{\mathrm{R}}$ fecal isolates obtained in this study ranged from 2.32 to 2.56 , allowing species-specific identification (Table 1). Cef ${ }^{\mathrm{R}}$ resistant enteric bacteria were isolated from six $(60 \%)$ out of the ten shelters sampled in this study. Of the 59 dogs sampled in this study, 16 (27.1\%; 95\% CI: 16.4-40.3\%) tested positive for carriage of $\mathrm{Cef}^{\mathrm{R}}$ bacteria. These $16 \mathrm{dogs}$ yielded a total of $18 \mathrm{Cef}^{\mathrm{R}}$ resistant enteric bacteria (Table 1). A single/mono culture of $\mathrm{Cef}^{\mathrm{R}}$ E. coli was isolated from 13 out of $16 \operatorname{dogs}(81.2 \%)$. The remaining three dogs (18.8\%) yielded a mono culture of Acinetobacter baumannii (dog ID: CR14), mixed culture 


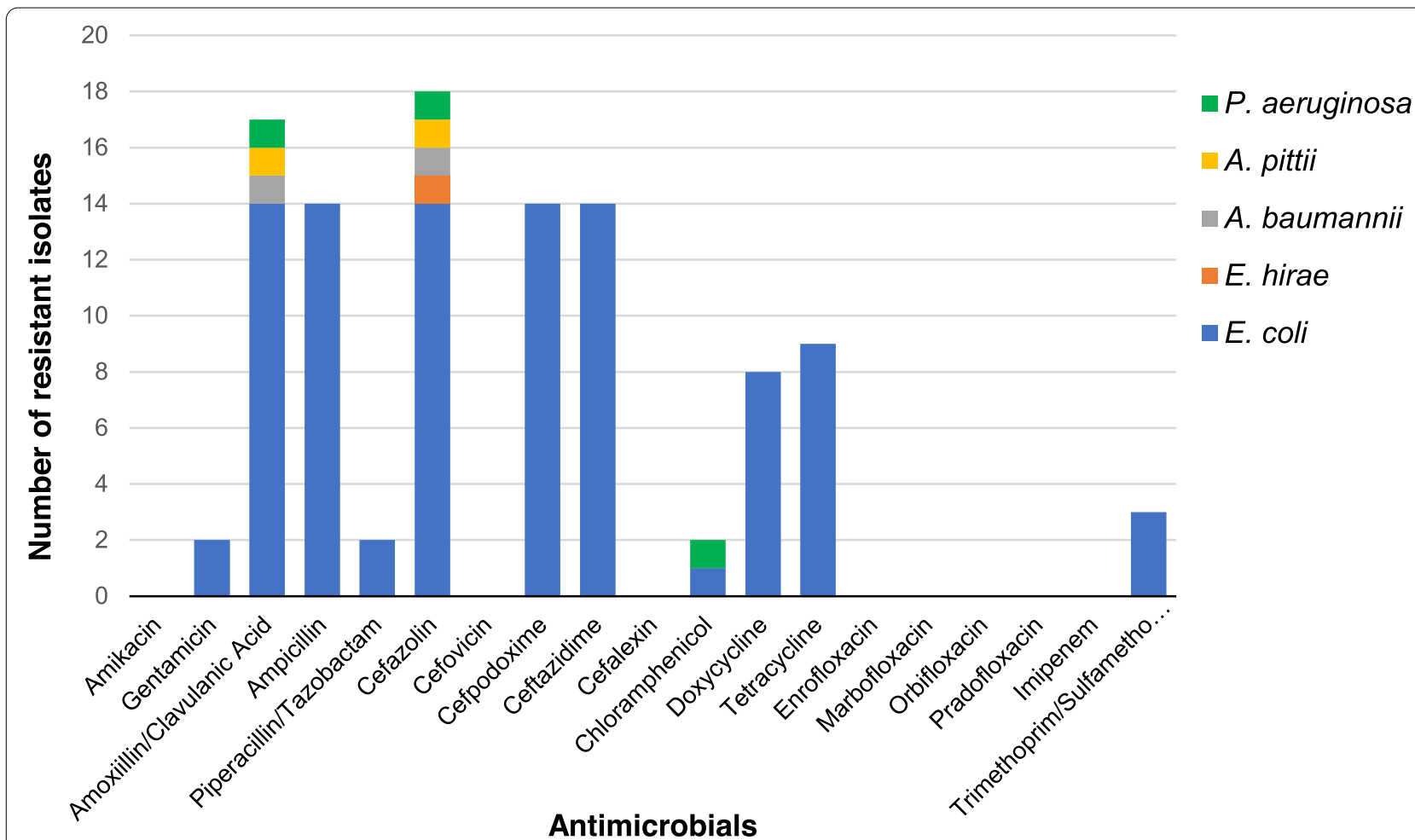

Fig. 2 Antimicrobial resistance of bacterial isolates

of $\mathrm{Cef}^{\mathrm{R}}$ E. coli and Enterococcus hirae (dog ID: CR12) and a mixed culture of Acinetobacter pitii and Pseudomonas aeruginosa ( $\operatorname{dog}$ ID: CR15). Among the $\mathrm{Cef}^{\mathrm{R}}$-positive dogs, the mean age was 1.9 years (range 2 months to 5 years), and the mean fecal score was 3 (range 2-6). Of note, 5 out of $6(83.33 \%)$ samples from shelter SL demonstrated cephalosporin resistance, accounting for nearly $32 \%$ of all $\mathrm{Cef}^{\mathrm{R}}$ bacteria isolated in this study. Only the variables sex and shelter when analyzed at the state-level had any statistical meaning due to small sample size and number of positives. State-level analysis showed a significant difference ( $p$-value $=0.049)$ among the three states in terms of dogs having $\mathrm{Cef}^{\mathrm{R}}$ enteric bacteria. At the state-level, Tennessee reported $45.8 \%(11 / 24 ; 95 \%$ CI: 25.6-67.2\%), followed by Kentucky (4/19, 21.2\%; 95\% CI: 6.1-45.6\%), and Virginia (2/16, 12.5\%; 95\% CI: 1.6-38.4\%). Shelter SL is located within Tennessee which likely influenced the results.

\section{Occurrence of antimicrobial resistance}

Antimicrobial susceptibilities of $\mathrm{Cef}^{\mathrm{R}}$ isolates $(\mathrm{n}=18)$ to a broad range of antibiotics that are relevant to companion animals were tested. $\mathrm{Cef}^{\mathrm{R}}$ enteric bacteria isolated in this study also showed resistance to amoxicillin-clavulanate $(\mathrm{n}=17)$, ampicillin $(\mathrm{n}=14)$, cefazolin $(\mathrm{n}=18)$, cefpodoxime $(n=14)$, ceftazidime $(n=14)$, chloramphenicol $(n=2)$, doxycycline $(n=8)$, gentamicin $(n=2)$, piperacillin $(n=2)$, tetracycline $(n=9)$, and trimethoprim/sulfamethoxazole $(\mathrm{n}=3)$ (Fig. 2).

Seventeen (94.4\%) Cef $^{\mathrm{R}}$ isolates were resistant to more than one antibiotic (Fig. 3). Of the 14 E. coli isolates, 11 (78.6\%) isolates exhibited MDR phenotype (resistance to three or more antibiotic classes). All $E$. coli isolates demonstrated resistance to amoxicillin/clavulanic acid, ampicillin, cefazolin, cefpodoxime, and ceftazidime. Eight out of $14 \mathrm{E}$. coli isolates were resistant to doxycycline; $9 / 14$ to tetracycline; $3 / 14$ to trimethoprim/sulfamethoxazole, $2 / 14$ to gentamicin and piperacillin, and 1 to chloramphenicol (Fig. 3). One E. coli isolate (CR03) demonstrated resistance to 9 of the tested antimicrobials (Fig. 3). Isolates from different dogs within a same shelter had same antimicrobial resistance profiles, for example, isolates CR06 and CR07 (shelter UC); CR08, CR09, CR11, CR12, and CR13 (shelter SL); CR14 and CR15A (shelter JO); CR16 and CR17 (shelter KW) (Fig. 3).

\section{Discussion}

Zoonotic and MDR enteric bacteria in shelter dogs pose a serious animal and public health concern. These dogs could serve as a reservoir of infections for other dogs, shelter worker or potential adopters. As noted earlier, some antimicrobials, such as extended spectrum 


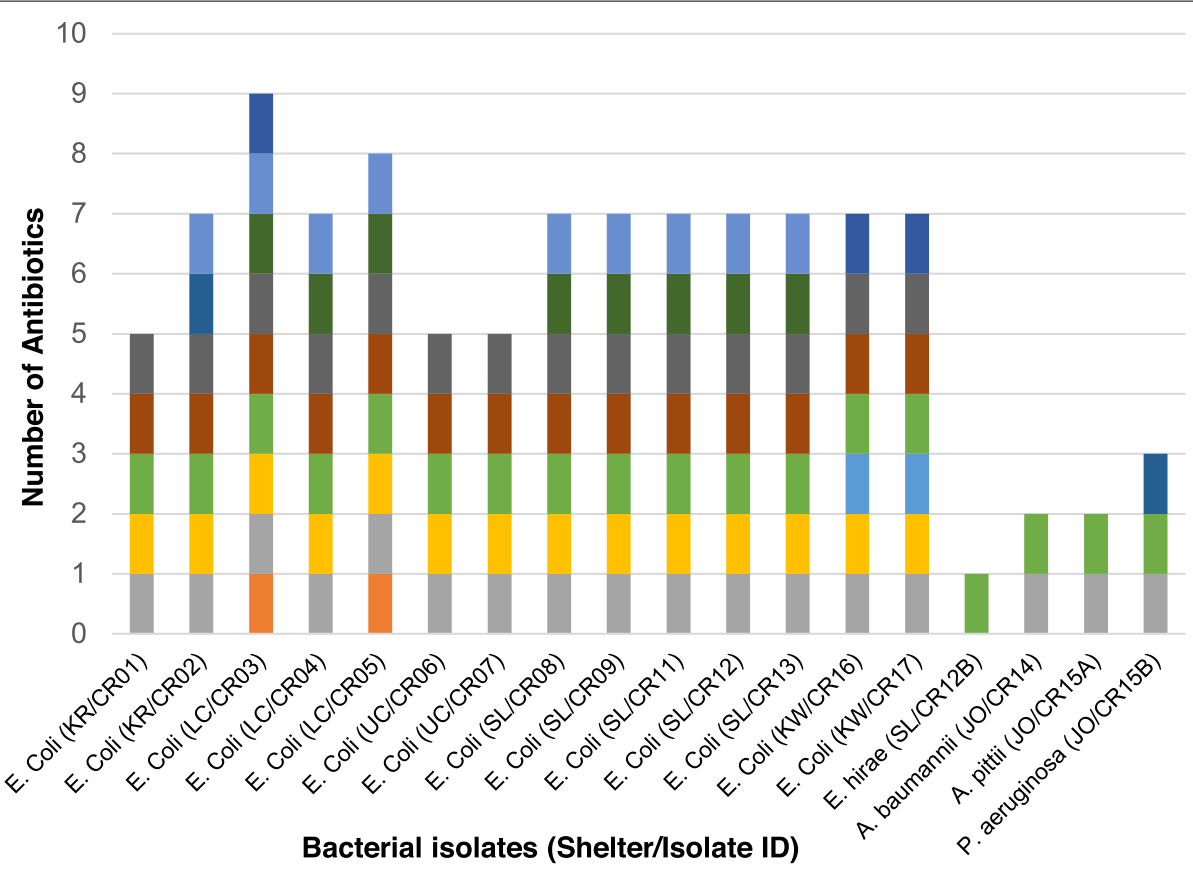

Gentamicin
Ampicillin
Cefazolin
Ceftazidime
Doxycycline
- Trimethoprim/Sulfamethoxazole

Amoxiillin/Clavulanic Acid - Piperacillin/Tazobactam

- Cefpodoxime

- Chloramphenicol

- Tetracycline

Fig. 3 Multi-drug resistance patterns of individual bacterial isolates

cephalosporins, are listed as critical antibiotics for treating bacterial infections in both humans and animals [2, 3]. The occurrence of $\mathrm{Cef}^{\mathrm{R}}$ enteric bacteria in shelter dogs in this study was $27.1 \%(16 / 59)$. These data corroborate with a recent study conducted in Ontario, Canada where average frequency of fecal carriage of $\mathrm{Cef}^{\mathrm{R}}$ enteric bacteria in apparently healthy dogs was $26.5 \%$ [24].

The approach of initial selection for resistance to the third-generation cephalosporin (ceftiofur), has been used previously in cattle and poultry $[25,26]$. Here, we employed similar approach to selectively isolate enteric bacteria that are not only resistant to cephalosporins, but also resistant to other antibiotic classes. For instance, 11 out of $14 \mathrm{E}$. coli isolates recovered in this study displayed MDR phenotype. The other common resistances noted in these isolates were against classes of antimicrobials that have been used for decades: penicillin, sulfonamide, aminoglycosides, and tetracycline. These findings are also consistent with those of Zhang et al (2018) in their study of fecal samples from dog parks and clinical settings.

A statistical association was found between the shelter of provenance and the presence of AMR in feces of the sampled dogs. While shelter characteristics were not recorded, the authors informally observed the shelters while collecting the samples. The shelters varied greatly in size, age of construction, training of personnel, stocking density, and overall perception of cleanliness. Interestingly, there were similar resistance profiles present within the population of individual shelters. For instance, E. coli isolates CR06 and CR07 in shelter UC, E. coli isolates CR08, CR09, CR11, CR12, and CR13 in shelter SL, E. coli isolates CR16 and CR17 in shelter KW, and A. baumannii and $A$. pittii isolates CR14 and CR15A in shelter JO had similar resistance profiles. These data suggest that dog-to-dog or point source transmission was likely occurring via environmental contamination or direct contact during socialization, even though the dogs were individually housed within each shelter. This provides an area for future investigation covering biosecurity, housing design, education, and disinfection processes to elucidate the horizontal transmission of resistant bacteria.

In addition, we found that $8(13.5 \%)$ and $14(23.7 \%)$ fecal samples tested in this study were positive for $C$. jejuni and cpa-positive C. perfringens. Both C. jejuni 
and $C$. perfringens are considered zoonotic pathogens $[12,22]$. Although likely, it is currently unknown if any of these bacteria are transmitted from shelter dogs or environment to other dogs or people in proximity within these shelters. Other research groups have demonstrated the potential for transmission of different bacterial pathogens between dogs and humans. Recently, 78\% of the Staphylococcus spp. isolated from healthy dogs were reported to exhibit multi-drug resistance $[6,27]$. Guardabassi and colleagues reported that $46 \%$ of pet owners carried the same strain of Staphylococcus pseudintermedius as their dogs with deep pyoderma [6]. Similarly, other studies have also reported transmission of methilicin-resistant staphylococci from companion dogs to people in close proximity $[28,29]$. Between 2016-2019, CDC reported two MDR Campylobacter outbreaks, which included almost 150 human cases, linked to contact with pet store puppies [30]. Although Salmonella was not detected in our study, zoonotic transmission of Salmonella from dogs to human has been reported [31-36]. The carriage and potential for transmission of zoonotic bacterial pathogens such as Campylobacter between clinically ill companion animals and humans is not a novel concept [19, 37]. However, this data shows that apparently healthy shelter dogs can be carriers of zoonotic and MDR enteric bacteria and may pose a hazard for pet owners, an increased occupational risk for animal care and veterinary staff, as well as a need for further research on this topic. Several bacterial species isolated in this study are known opportunistic human pathogens. For example, dog feces serve as a potential reservoir for $E$. coli with potential for extraintestinal infections such as urinary tract infections in humans [38-40]. The pathogen-AMR combinations detected in the current study have been identified as significant human pathogens under GLASS surveillance [41]. The results of interest include $E$. coli with resistance to penicillins, third and fourth generation cephalosporins, sulfonamides/trimethoprim. Although Acinetobacter spp. is on the GLASS surveillance list, the isolates in this study showed resistance only to penicillins and cephalosporins, which are not the antibiotic classes of interest. The ecology, epidemiology, and potential public health significance of the organisms in this specific situation of animal shelters is currently unknown and requires further investigation $[42,43]$.

One of the inherent limitations for this study is the lack of medical history for each dog. For example, the prior antimicrobial use of these dogs is unknown, as they were an undisclosed mix of captured and owner-surrendered dogs. It is worthwhile to note that exposure to multiple antimicrobials is not uncommon in many shelter situations [44] as upper respiratory (canine infectious respiratory disease-CIRD), gastrointestinal and heartworm diseases are frequently encountered in shelters. Broad-spectrum antibiotics such as doxycycline, may be used as part of treatment regimen for the above conditions [45]. Additional antibiotic treatments in shelters include amoxicillin-clavulanate, azithromycin, enrofloxacin, and trimethoprim-sulfonamide [46]. These antibiotics can select for multi-drug resistant bacteria within the shelter population, which may explain why resistance against all of these antibiotics were observed in the isolates in our study. It is possible that use of one or more antibiotics may have not only selected for MDR bacteria in the dogs screened in this study, but also leading to persistence and potential transmission between dogs.

\section{Conclusions}

The results of this study show that shelter dog population can serve as a potential reservoir for zoonotic and MDR enteric bacteria and raise a possibility transmission to humans in proximity. Noting that many shelters allow the volunteers and general public to interact freely with these animals prior to adoption, the potential risk may not be just limited to the shelter staff. In case of vulnerable groups (geriatric, immunocompromised, undergoing chemotherapy), a screening protocol for zoonotic and AMR pathogens prior to adoption may be considered. Microbiome diagnostics may be of value in these situations and their usefulness is currently under investigation in our lab.

\section{Methods}

Ethics statement

This study was conducted on freely voided fecal samples collected under a protocol that was exempted by the Institutional Animal Care and Use Committee at the Lincoln Memorial University. Informed consent was obtained from the animal shelter directors to collect and use the fecal samples for research.

\section{Sample collection}

During Summer 2019, fecal samples were collected from 59 apparently healthy dogs, varying in sex and age, housed in 10 different shelters in the Appalachian Region of Kentucky, Tennessee, and Virginia (Fig. 4). The animals were apparently healthy, of varied ages and sexes at the time of sample collection. Fresh fecal samples (9-50 g) were collected from freshly voided samples in the individual kennel. Upon collection into plastic zip-top bags, samples were immediately placed on ice and transported to the lab for further processing. Demographic information including shelter location, animal age, breed, sex, and fecal score (Purina scale) were recorded for each dog (Table 1). 
A.

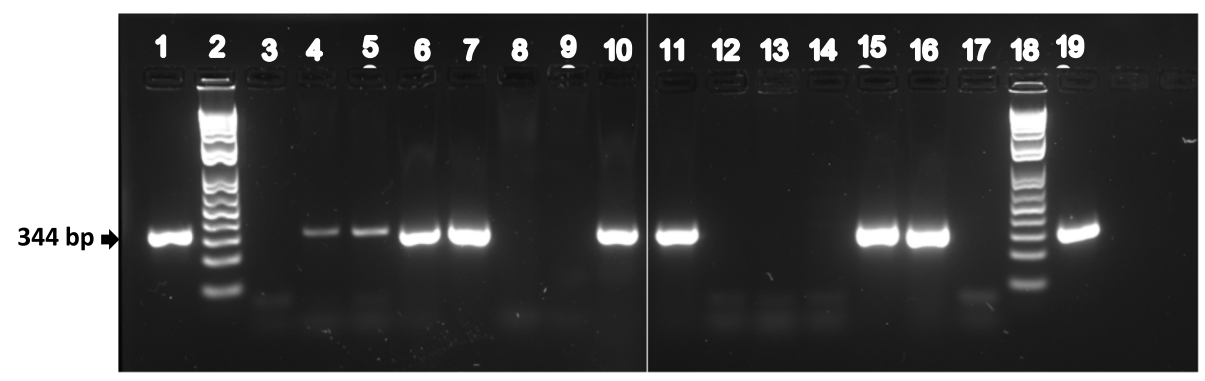

B.

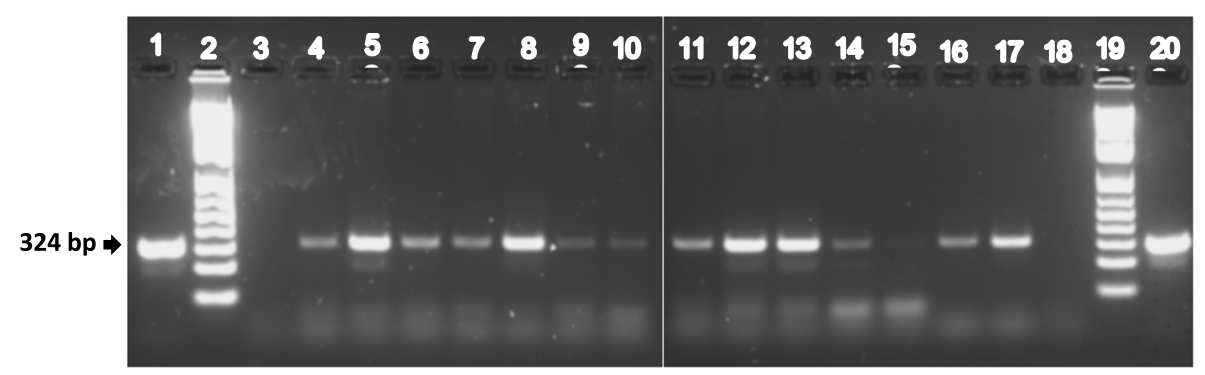

Fig. 4 PCR identification of C. jejuni and cpa-positive C.perfringens. For C. jejuni identification A: Lanes 1 and 19, C. jejuni genomic DNA; lanes 2 and 18, $100 \mathrm{bp}$ DNA ladder; lanes 3 and 17, no template control; lanes 4, 5, 6, 7, 10, 11, 15 and 16, C. jejuni hipO positive samples; lanes 8, 9, 12, 13 and 14, C. jejuni hipO gene negative samples. For C. perfringens identification. Samples in lanes 1-10 and 11-19 were run on the top and bottom halves of the same gel, respectively. B: Lanes 1 and 20, C. perfringens genomic DNA; lanes 2 and 19, 100bp DNA ladder; lanes 3 and 18, no template control; lanes 4, 5, 6, 7, 8, 9, 10, 11, 12, 13 and 14, 15, 16 and 17, C. perfringens cpa gene positive samples. Lane 15 has a faint band. All samples were tested at least twice. Samples in lanes 1-10 and 11-20 were run on the top and bottom halves of the same gel, respectively

\section{PCR screening for C. jejuni, C. perfringens and Salmonella}

Total genomic DNA was extracted from each fecal sample $(n=59)$ using QIAamp DNA Stool Mini Kit following manufacturer's instructions (Qiagen, Germantown, $\mathrm{MD})$. Extracted DNA were quantified and screened for detection of C. jejuni, C. perfringens and Salmonella by PCR as follows. For the detection of C. jejuni, a PCR targeting hipO gene was used as described previously [47]. Each $25 \mu \mathrm{L}$ PCR reaction contained 1.25 U FastStart Taq Polymerase (Roche Diagnostics), 1X PCR buffer (Applied Biosystems), $0.2 \mu \mathrm{M}$ hipO-F (5' GACTTCGTGCAGATA TGGATGCTT), $0.2 \mu \mathrm{M}$ hipO-R (5' GCTATAACTATC CGAAGAAGCCATCA), $5 \mu \mathrm{L}$ of fecal DNA, and thermal conditions as described previously [47]. For amplification of cpa gene from $C$. perfringens, each $25 \mu \mathrm{L}$ PCR mixture consisted of $12.5 \mu \mathrm{L}$ of DreamTaq PCR master mix (Thermo Fisher Scientific, CA, USA), $0.25 \mu \mathrm{M}$ cpa1F primer (5'-GCTAATGTTACTGCCGTTGA-3'), $0.25 \mu \mathrm{M}$ cpa1 $\mathrm{R}$ primer (5'-CCTCTGATACATCGTGTA AA- $\left.3^{\prime}\right)$, and $1 \mu \mathrm{L}$ of fecal DNA. The PCR was performed following method described previously [48]. PCR product size for C. perfringens was $324 \mathrm{bp}$. For PCR detection of Salmonella, a well-conserved Salmonella gene invA was targeted, as described previously [48]. Briefly, each $25 \mu \mathrm{L}$ reaction consisted of $0.04 \mu \mathrm{M}$ invA_F primer $\left(5^{\prime}\right.$ GTGTCCTTTGGTATTAATCC- $\left.3^{\prime}\right), 0.04 \mu \mathrm{M}$ invA_R (5'-GTCTGAGCACTTCTTTAAG-3') primer, $12.5 \mu \mathrm{L}$ of DreamTaq PCR master mix (Thermo Fisher Scientific, $\mathrm{CA}, \mathrm{USA})$, and $2 \mu \mathrm{L}$ of fecal DNA. The thermal conditions consisted of $95{ }^{\circ} \mathrm{C}$ for $5 \mathrm{~min}$, followed by 39 cycles of $20 \mathrm{~s}$ at $95{ }^{\circ} \mathrm{C}, 20 \mathrm{~s}$ at $54{ }^{\circ} \mathrm{C}, 20 \mathrm{~s}$ at $72{ }^{\circ} \mathrm{C}$, and a final for $5 \mathrm{~min}$ at $72{ }^{\circ} \mathrm{C}$. PCR product size for Salmonella was $250 \mathrm{bp}$. Positive controls (genomic DNA extracted from a reference strain of each tested bacteria) and negative control (water) were included during each PCR run. PCR amplicons were analyzed by $1.5 \%$ agarose gel electrophoresis under standard conditions and stained by GelGreen Nucleic Acid Gel Stain (Biotium, Inc., Fremont, CA).

\section{Isolation of salmonella}

For isolation of Salmonella, $1 \mathrm{~g}$ of fecal sample was resuspended in $10 \mathrm{ml}$ of buffered peptone water (BPW) and incubated overnight at $37^{\circ} \mathrm{C}$ for $24 \mathrm{~h}$. Subsequently, 10 drops of sample-BPW suspension were transferred 
to $10 \mathrm{ml}$ of iodine-supplemented tetrathionate broth (TTB, Hardy Diagnostics) and incubated at $37^{\circ} \mathrm{C}$ for 24 h. Next, $10 \mu \mathrm{l}$ of sample-TTB suspension was inoculated on XLT-4 agar (Hardy Diagnostics) plates and plates were incubated at $37^{\circ} \mathrm{C}$ for up to $24 \mathrm{~h}$. Suspect Salmonella colonies were purified by replica plating and stored at $-80^{\circ} \mathrm{C}$ in $15 \%(\mathrm{v} / \mathrm{v})$ phosphate-buffered glycerol.

\section{Isolation of ceftiofur-resistant enteric bacteria}

One gram of fecal sample was resuspended in $5 \mathrm{ml}$ of phosphate buffered saline (PBS) and incubated at room temperature for $5 \mathrm{~min}$. Fifty and $150 \mu \mathrm{l}$ of sample were transferred onto a MacConkey agar plate supplemented with Ceftiofur $(8 \mu \mathrm{g} / \mathrm{ml})$ and evenly spread over the surface of the agar as described previously [25]. The plates were then incubated at $37^{\circ} \mathrm{C}$ for 15 to $18 \mathrm{~h}$. Two to three colonies representing a unique colony morphotype were selected, transferred to $5 \mathrm{ml} \mathrm{LB}$ containing Ceftiofur (8 $\mu \mathrm{g} / \mathrm{ml})$, mixed well and then incubated again at $37^{\circ} \mathrm{C}$ for 15 to $18 \mathrm{~h}$. Following incubation, the cultures were preserved in $15 \%(\mathrm{v} / \mathrm{v})$ glycerol and frozen at $-80^{\circ} \mathrm{C}$. Approximately $1 \mu \mathrm{l}$ of the sample was taken from the frozen stock, streaked onto a blood agar plate, and incubated at $37^{\circ} \mathrm{C}$ for 15 to $18 \mathrm{~h}$. These plates were used for identification and characterization of isolates.

\section{Identification and characterization of isolates}

The individual colonies from pure cultures were identified by MALDI-TOF (Bruker, Billerica, MA) following manufacturer's instructions. The bacteria with scores above 2.0 were identified at the species level. The isolates from pure cultures underwent antimicrobial susceptibility testing by broth microdilution method using commercial plates (COMPGN1F and COMPGP1F, Trek Sensititer; ThermoFisher Scientific, Grand Island, NY, USA) in accordance to the guidelines established by the Clinical and Laboratory Standard Institute (CLSI, 2017). The concentrations $(\mu \mathrm{g} / \mathrm{ml})$ of the antimicrobials in COMPGN1F panel included Amikacin $(4-32)$; Amoxicillin / clavulanic acid 2:1 ratio $(0.25 / 0.12$ - 8/4); Ampicillin (0.25 - 8); Cefazolin (1 - 32); Cefovecin $(0.25-8)$; Cefpodoxime $(1-8)$; Ceftazidime $(4-16)$; Cephalexin (0.5 - 16); Chloramphenicol (2 - 32); Doxycycline $(0.25$ - 8); Enrofloxacin $(0.12-4)$; Gentamicin (0.25 - 8); Imipenem (1 - 8); Marbofloxacin (0.12 - 4); Orbifloxacin (1 - 8); Piperacillin / tazobactam (8/4 - 64/4); Pradofloxacin $(0.25-2)$; Tetracycline $(4-16)$; Trimethoprim/ sulfamethoxazole $(0.5 / 9.5$ - 4/76). The concentration of antimicrobials in COMPGP1F panel included Amikacin (16 - 32); Amoxicillin / clavulanic acid 2:1 ratio (0.25/0.12 - 8/4); Ampicillin (0.25 - 8); Cefazolin (2 - 4); Cefovecin (0.06 - 8); Cefpodoxime $(2-8)$; Cephalothin
(2 - 4); Chloramphenicol (8 - 32); Clindamycin (0.5 - 4); Doxycycline $(0.12-0.5)$; Enrofloxacin $(0.25-4)$; Erythromycin (0.25 - 4); Gentamicin (4 - 16); Imipenem (1 - 4); Marbofloxacin (1 - 4); Minocycline (0.5 - 2); Nitrofurantoin $(16-64)$; Oxacillin $+2 \% \mathrm{NaCl}(0.25-2)$; Penicillin (0.06 - 8); Pradofloxacin (0.25 - 2); Rifampin $(1-2)$; Tetracycline $(0.25-1)$; Trimethoprim/sulfamethoxazole $(2 / 38$ - 4/76); Vancomycin $(1-16)$. S. aureus ATCC 29213, Streptococcus pneumoniae ATCC 46619, Enterococcus faecalis ATCC 29212, or Escherichia coli ATCC 25922 were tested weekly as quality assurance to validate the test. The interpretation of antimicrobial susceptibilities was based upon the most recent CLSI guidelines as provided by the manufacturer. For $E$. coli, the isolate that were resistant to three or more antibiotic classes were labeled as MDR following the CDC-NARMS guidelines (https://www.cdc.gov/narms/resources/gloss ary.html). Because of their intrinsic antibiotic resistance, Pseudomonas spp. and Acinetobacter spp. were labeled MDR only if they were resistant to two or more of antibiotic classes for which they are not known to be intrinsically resistant (Shah et al., 2019).

\section{Statistical analysis}

Statistical analysis was performed using SPSS 26 (IBM, New York). Briefly, test results for $C$. perfringens, $C$. jejuni and $\mathrm{Cef}^{\mathrm{R}}$ enteric bacteria were compared to variables: shelter location, age, sex, and fecal score using chi-square test or Fisher's exact test. Breed was not included in analysis due to too much variation in data collected. Additionally, shelter locations were grouped at state-level and dogs were categorized as $<1$ year old or $\geq 1$ year old to improve results of statistical analysis. A $p$-value of $<0.05$ was considered significant.

\section{Abbreviations \\ AMR: Antimicrobial Resistance; Cef ${ }^{R}$ : Cephalosporin Resistant; CDC: Centers for Disease Control and Prevention; CGR: Cumberland Gap Region; CLSI: Clinical and Laboratory Standard Institute; GLASS: Global Antimicrobial Resistance Surveillance System; MDR: Multi-Drug Resistant; MOUs: Memoranda of Under- standing; WHO: World Health Organization.}

\section{Acknowledgements}

We thank Michael Stonerook for helpful comments on the manuscript.

\section{Authors' contributions}

Conceived and designed the experiments: AV, DHS. Performed the experiments: KC, MT, KA, JM, EE, SL, AC. Analyzed the data: AV, DHS, KG, KC, CC. Wrote the paper: AV, DHS, KC, AC. All authors reviewed and approved the manuscript.

\section{Funding}

This project was funded through an intramural grant from Lincoln Memorial University College of Veterinary Medicine. Funders had no role in the design of the study and collection, analysis, and interpretation of data and in writing the manuscript. 


\section{Availability of data and materials}

The datasets used and/or analysed during the current study are available from the corresponding author on reasonable request.

\section{Declarations}

\section{Ethics approval and consent to participate}

This study was conducted on freely voided fecal samples collected under a protocol that was exempted by the Institutional Animal Care and Use Committee at the Lincoln Memorial University. Informed consent was obtained from the animal shelter directors to collect and use the fecal samples for research.

\section{Consent for publication}

Not applicable

\section{Competing interests}

The authors declare that they have no competing interests.

\section{Author details}

${ }^{1}$ College of Veterinary Medicine, Harrogate, USA. ${ }^{2}$ Center for Infectious, Zoonotic and Vector-borne diseases, Harrogate, USA. ${ }^{3}$ Center for Animal and Human Health in Appalachia, Lincoln Memorial University, 6965 Cumberland Gap Parkway, Harrogate, TN 37752, USA. ${ }^{4}$ Veterinary Diagnostic Laboratory, University of Kentucky, Lexington, Kentucky, USA. ${ }^{5}$ Department of Veterinary Microbiology \& Pathology, Washington State University College of Veterinary Medicine, Pullman, Washington, USA.

Received: 19 April 2021 Accepted: 13 September 2021 Published online: 25 September 2021

\section{References}

1. Schmiedel J, Falgenhauer L, Domann E, Bauerfeind R, PrengerBerninghoff E, Imirzalioglu C, et al. Multiresistant extended-spectrum $\beta$-lactamase-producing Enterobacteriaceae from humans, companion animals and horses in central Hesse, Germany. BMC Microbiol. 2014;14:187.

2. OIE. OIE List of Antimicrobial Agents of Veterinary Importance. 2019.

3. WHO. Critically important antimicrobials for human medicine. 2019;6th revision.

4. Saputra S, Jordan D, Mitchell T, Wong HS, Abraham RJ, Kidsley A, et al. Antimicrobial resistance in clinical Escherichia coli isolated from companion animals in Australia. Vet Microbiol. 2017;211:43-50.

5. Costa D, Poeta P, Sáenz Y, Coelho AC, Matos M, Vinué L, et al. Prevalence of antimicrobial resistance and resistance genes in faecal Escherichia coli isolates recovered from healthy pets. Vet Microbiol. 2008;127(1-2):97-105

6. Guardabassi L, Loeber ME, Jacobson A. Transmission of multiple antimicrobial-resistant Staphylococcus intermedius between dogs affected by deep pyoderma and their owners. Vet Microbiol. 2004;98(1):23-7.

7. Johnson JR, Clabots C, Kuskowski MA. Multiple-Host Sharing, Long-Term Persistence, and Virulence of Escherichia coli Clones from Human and Animal Household Members. J Clin Microbiol. 2008;46(12):4078-82.

8. Harada K, Okada E, Shimizu T, Kataoka Y, Sawada T, Takahashi T. Antimicrobial resistance, virulence profiles, and phylogenetic groups of fecal Escherichia coli isolates: A comparative analysis between dogs and their owners in Japan. Comp Immunol Microbiol Infect Dis. 2012;35(2):139-44.

9. Umeda K, Hase A, Matsuo M, Horimoto T, Ogasawara J. Prevalence and genetic characterization of cephalosporin-resistant Enterobacteriaceae among dogs and cats in an animal shelter. J Med Microbiol. 2019;68(3):339-45.

10. Lloyd DH. Reservoirs of Antimicrobial Resistance in Pet Animals. Clin Infect Dis. 2007;45 Suppl 2:S148-52.

11. APAA. National Pet Owners Survey. 2019

12. Rossi M, Hänninen ML, Revez J, Hannula M, Zanoni RG. Occurrence and species level diagnostics of Campylobacter spp., enteric Helicobacter spp. and Anaerobiospirillum spp. in healthy and diarrheic dogs and cats. Vet Microbiol. 2008;129(3-4):304-14.
13. Kapperud G, Skjerve E, Bean NH, Ostroff SM, Lassen J. Risk factors for sporadic Campylobacter infections: results of a case-control study in southeastern Norway. J Clin Microbiol. 1992;30(12):3117-21.

14. Adak GK, Cowden JM, Nicholas S, Evans HS. The Public Health Laboratory Service national case-control study of primary indigenous sporadic cases of campylobacter infection. Epidemiol Infect. 1995;115(1):15-22.

15. Fullerton $K E$, Ingram LA, Jones TF, Anderson BJ, McCarthy PV, Hurd S, et al. Sporadic Campylobacter Infection in Infants. Pediatr Infect Dis J. 2007:26(1):19-24.

16. Gillespie IA, O’Brien SJ, Adak GK, Tam CC, Frost JA, Bolton FJ, et al. Point source outbreaks of Campylobacter jejuni infection--are they more common than we think and what might cause them? Epidemiol Infect. 2003;130(3):367-75.

17. Tam CC, Higgins CD, Neal KR, Rodrigues LC, Millership SE, O'Brien SJ. Chicken Consumption and Use of Acid-Suppressing Medications as Risk Factors for Campylobacter Enteritis, England. Emerg Infect Dis. 2009;15(9):1402-8.

18. Tenkate TD, Stafford RJ. Risk factors for campylobacter infection in infants and young children: a matched case-control study. Epidemiol Infect. 2001:127(3):399-404.

19. Damborg P, Olsen KEP, Moller Nielsen E, Guardabassi L. Occurrence of Campylobacter jejuni in Pets Living with Human Patients Infected with C. jejuni. J Clin Microbiol. 2004;42(3):1363-4.

20. Wright JG, Tengelsen LA, Smith KE, Bender JB, Frank RK, Grendon JH, et al. Multidrug-resistant Salmonella Typhimurium in Four Animal Facilities. Emerg Infect Dis. 2005;11(8):1235-41.

21. Reimschuessel R, Grabenstein M, Guag J, Nemser SM, Song K, Qiu J, et al. Multilaboratory Survey To Evaluate Salmonella Prevalence in Diarrheic and Nondiarrheic Dogs and Cats in the United States between 2012 and 2014. J Clin Microbiol. 2017;55(5):1350-68.

22. Marks SL, Rankin SC, Byrne BA, Weese JS. Enteropathogenic Bacteria in Dogs and Cats: Diagnosis, Epidemiology, Treatment, and Control. J Vet Intern Med. 2011;25(6):1195-208.

23. Steneroden KK, Hill AE, Salman MD. Zoonotic Disease Awareness in Animal Shelter Workers and Volunteers and the Effect of Training. Zoonoses Public Health. 2011;58(7):449-53.

24. Zhang PLC, Shen X, Chalmers G, Reid-Smith RJ, Slavic D, Dick H, et al. Prevalence and mechanisms of extended-spectrum cephalosporin resistance in clinical and fecal Enterobacteriaceae isolates from dogs in Ontario, Canada. Vet Microbiol. 2018;213:82-8.

25. Shah DH, Board MM, Crespo R, Guard J, Paul NC, Faux C. The occurrence of Salmonella, extended-spectrum $\beta$-lactamase producing Escherichia coli and carbapenem resistant non-fermenting Gram-negative bacteria in a backyard poultry flock environment. Zoonoses Public Health. 2020;67(6):742-53.

26. Mir RA, Weppelmann TA, Johnson JA, Archer D, Morris JG, Jeong KC. Identification and Characterization of Cefotaxime Resistant Bacteria in Beef Cattle. PLoS One. 2016;11(9):e0163279.

27. Davis JA, Jackson CR, Fedorka-Cray PJ, Barrett JB, Brousse JH, Gustafson J, et al. Carriage of methicillin-resistant staphylococci by healthy companion animals in the US. Lett Appl Microbiol. 2014:59(1):1-8.

28. Loeffler A, Pfeiffer DU, Lloyd DH, Smith H, Soares-Magalhaes R, Lindsay JA. Meticillin-resistant Staphylococcus aureus carriage in UK veterinary staff and owners of infected pets: new risk groups. J Hosp Infect. 2010;74(3):282-8.

29. Loeffler A, Boag AK, Sung J, Lindsay JA, Guardabassi L, Dalsgaard A, et al. Prevalence of methicillin-resistant Staphylococcus aureus among staff and pets in a small animal referral hospital in the UK. J Antimicrob Chemother. 2005;56(4):692-7.

30. CDC. Outbreak of Multidrug-resistant Campylobacter Infections Linked to Contact with Pet Store Puppies 2019.

31. Imanishi M, Rotstein DS, Reimschuessel R, Schwensohn CA, Woody DH Davis SW, et al. Outbreak of Salmonella enterica serotype Infantis infection in humans linked to dry dog food in the United States and Canada, 2012. J Am Vet Med Assoc. 2014;244(5):545-53.

32. Watt J, DeCapito T. The frequency and distribution of Salmonella types isolated from man and animals in Hidalgo county, Texas. Am J Epidemiol. 1950:51(3):343-52.

33. Wolff AH, Henderson ND, McCallum GL. Salmonella from Dogs and the Possible Relationship to Salmonellosis in Man. Am J Public Health Nations Health. 1948:38(3):403-8. 
34. Morse EV, Duncan MA, Estep DA, Riggs WA, Blackburn BO. Canine salmonellosis: A review and report of dog to child transmission of Salmonella enteritidis. Am J Public Health. 1976;66(1):82-4.

35. Neumann HH. Dogs and cats as sources of salmonellosis. Conn Med. 1974;38(6):335. undefined

36. Sato Y, Mori T, Koyama T, Nagase H. Salmonella Virchow Infection in an Infant Transmitted by Household Dogs. J Vet Med Sci. 2000;62(7):767-9.

37. Gras LM, Smid JH, Wagenaar JA, Koene MGJ, Havelaar AH, Friesema IHM et al. Increased risk for Campylobacter jejuni and C. coli infection of pet origin in dog owners and evidence for genetic association between strains causing infection in humans and their pets. Epidemiol Infect. 2013;141(12):2526-35.

38. Johnson JR, O'Bryan TT, Low DA, Ling G, Delavari P, Fasching C, et al. Evidence of Commonality between Canine and Human Extraintestinal Pathogenic Escherichia coli Strains That ExpresspapG Allele III. Infect Immun. 2000;68(6):3327-36.

39. LeCuyer TE, Byrne BA, Daniels JB, Diaz-Campos DV, Hammac GK, Miller CB, et al. Population Structure and Antimicrobial Resistance of Canine Uropathogenic Escherichia coli. J Clin Microbiol. 2018;56(9).

40. Johnson JR, Stell AL, Delavari P, Murray AC, Kuskowski M, Gaastra W. Phylogenetic and Pathotypic Similarities between Escherichia coli Isolates from Urinary Tract Infections in Dogs and Extraintestinal Infections in Humans. J Infect Dis. 2001;183(6):897-906.

41. WHO. Global Antimicrobial Resistance Surveillance System (GLASS) Report: Early Implementation. 2019.
42. Woolhouse MEJ, Haydon DT, Antia R. Emerging pathogens: the epidemiology and evolution of species jumps. Trends Ecol Evol. 2005;20(5):238-44

43. Wood CL. Environmental change and the ecology of infectious disease. Science. 2014;346(6214):1192.

44. Pesavento PA, Murphy BG. Common and Emerging Infectious Diseases in the Animal Shelter. Vet Pathol. 2014;51(2):478-91.

45. Papich MG. Considerations for using minocycline vs doxycycline for treatment of canine heartworm disease. Parasit Vectors. 2017:10(Suppl 2):493.

46. Sykes J, Greene C. Infectious Diseases of the Dog and Cat. 2011;4th edition.

47. Persson S, Olsen KE. Multiplex PCR for identification of Campylobacter coli and Campylobacter jejuni from pure cultures and directly on stool samples. J Med Microbiol. 2005:54(Pt 11):1043-7.

48. Schlatter DC, Paul NC, Shah DH, Schillinger WF, Bary Al, Sharratt B, et al. Biosolids and Tillage Practices Influence Soil Bacterial Communities in Dryland Wheat. Microb Ecol. 2019;78(3):737-52.

\section{Publisher's Note}

Springer Nature remains neutral with regard to jurisdictional claims in published maps and institutional affiliations.
Ready to submit your research? Choose BMC and benefit from:

- fast, convenient online submission

- thorough peer review by experienced researchers in your field

- rapid publication on acceptance

- support for research data, including large and complex data types

- gold Open Access which fosters wider collaboration and increased citations

- maximum visibility for your research: over $100 \mathrm{M}$ website views per year

At BMC, research is always in progress.

Learn more biomedcentral.com/submissions 